\title{
Osteosarcoma of the Jaw: Radiographic Evidences and Differential Diagnosis
}

\author{
Luca Viganò $^{1^{*}}$, Elisa Bettoni ${ }^{2}$, Federica E. Salina ${ }^{2}$, Marta Damilano $^{2}$, Martina Sciarra $^{2}$, Sara Piccinini $^{2}$, Cinzia Casu $^{3}$
}

${ }^{1}$ DDS, Department of Oral Radiology, San Paolo Dental Building, University of Milano, Italy

${ }^{2}$ Univeristy of Milano, Italy

${ }^{3}$ DDS, Private Dental Practice, Cagliari, Italy

DOI: $10.36347 /$ sjds.2020.v07i10.002

| Received: 22.09.2020 | Accepted: 29.09.2020 | Published: 06.10.2020

*Corresponding author: Luca Viganò

Abstract

Original Research Article

The aim of our review is to give a complete picture of a rare condition such as the osteosarcoma of the jaw. Through the analysis of various case reports and retrospective cohort studies, the research in the literature about this topic allowed us to highlight its epidemiological, physiological, diagnostic and therapeutic aspects. In particular we tried to give greater emphasis to the X-ray aspects and diagnostic evidence of the pathology. At the epidemiological level, the osteosarcoma is a type of cancer that affects particularly young people, and for this reason most cases examined are distributed to individuals between 10 and 30 years, but we have not included exclusion criteria for this aspect. The research focused on the collection and analysis of case reports and retrospective studies from the newest to the oldest ones, as there are no substantial differences in the approach. Osteosarcomas (OS) of all sites represent $40 \%$ to $60 \%$ of primary malignant bone cancers. About $10 \%$ of osteosarcomas occur in the head and neck; most of them are in the mandible or in the maxilla. The JOS (Osteosarcoma of the jaws) represents 6-7\% of all primary osteosarcomas. The mandible is more commonly involved than the maxilla (from 1.5:1 to 2:13). In many cases there is an association with smoking, alcohol and pathologies such as Paget's disease, Li-Fraumeni syndrome, Sjogren's syndrome, bone diseases, treatment with chemotherapy and radiotherapy. Symptoms and signs most frequently reported by patients are swelling, loss of dental stability, pain, ulceration of mucosa, hypoesthesia and parestesia. At the X-ray level, diagnostic techniques such as orthopantomography are preferred, identifying radio-light or radio-opaque lesions, and periapic endoral x- rays, in which the presence of the enlarged periodontal ligament, the so-called Garrington sign and the "sunbeam" appearance, are highlighted. The use of CT and Magnetic resonance imaging has allowed better detection of the lesion in many cases. CT imaging is a valuable tool for surgical planning, which remains the gold standard in therapeutic approach for this type of cancer. There are three main histological types, including variants, fibroblastic, osteoblastic and condroblastic, the latter being the most represented. Due to the rarity of JOS, the protocols of diagnosis and treatment were formulated primarily referring to the guidelines adopted in the case of other osteosarcomas and only later they were refined for this particular type of cancer. It remains a little-known and studied pathology, in which the diagnosis is not always easy and clear.

Keywords: jaw, therapeutic aspects, pathology, Osteosarcomas (OS), diagnosis.

Copyright @ 2020: This is an open-access article distributed under the terms of the Creative Commons Attribution license which permits unrestricted use, distribution, and reproduction in any medium for non-commercial use (NonCommercial, or CC-BY-NC) provided the original author and source are credited.

\section{INTRODUCTION}

Osteosarcoma is a primary, malignant and rare bone tumor [1-3] characterized by the production of bone tissue or osteoid substance, with malignant tumor appearance along the edges of the lesion, due to a periostal reaction. It mainly affects long bones. In $2 / 3$ of the cases it affects the knee and the shoulder blade, but any bone could be potentially affected.

Craniofacial osteosarcoma is rare. It represents $1 \%$ of cancers in the head-neck district and $10 \%$ of all osteosarcomas. $4-7 \%$ of osteosarcomas affect the maxilla and $60 \%$ the mandible. The elective seat is the horizontal branch and the syphisal region. As regards the maxilla, all the locations of the bone are found with the same frequency [4-6, 2, 3, 7]. Currently, JOS is treated in a similar way to long bone osteosarcomas, despite biological and clinical differences. On average JOS develops a decade later than those of long bones and is believed to have a more benign clinical course, often showing little atypia with a lower incidence of metastatic diffusion $[1,3]$. 
In the maxilla, lesions are commonly observed in the alveolar crest, in the sinus and in the palate compared to the upper districts (cheekbone, orbit). There is no gender predisposition, but some authors consider a greater predisposition in women. In the study conducted by Rui Fernandes, the gender distribution consisted of 10 females and 6 males, corresponding to a ratio of 1.6. (2) Nearly $60 \%$ of osteosarcomas are observed in children and adolescents and about $10 \%$ emerge during the third decade of life [4-6, 8-10, 2].

The etiology of the primary form is not yet clear, but it could be correlated with genetic influences, pathologies or other environmental factors and therapeutic treatments (radiotherapy and chemotherapy). It is assumed to be caused by mutations in the oncosuppressor genes p53 and Rb (retinoblastoma). On the other hand, in some cases in patients' anamnesis who have a secondary form a history of trauma is reported. In many cases there is an association with smoking, alcohol and pathologies such as Paget's disease [11], Li- Fraumeni syndrome, Sjogren's syndrome and bone diseases or following radiotherapy $[11,12]$.

As it has been widely demonstrated in other studies, JOS can be associated with several histological features. Stromal cells can be mostly osteoblastic, condroblastic or fibroblastic. The most frequent osteosarcoma has a malignant tapered cell or a multifaceted stroma that produces osteoid or neoplastic bone. The production of osteoids and bones can range from small scattered fires to dense, irregular and intertwined beams and trabecoles, poorly formed and calcified irregularly with relatively small intervening stroma, which alternates areas of osteosclerosis with areas of osteolisis. Vascularization is generally quite rich and channels can range from capillary size to fairly large cavernous structures [6].

\section{METHODS AND SELECTION}

All types of studies published in English were included and treated with patients diagnosed with jaw osteosarcoma. The studies included case reports, cohort studies and case series retrospective studies that analyzed several patients.

\section{Research Methods for Identifying Studies}

Research has been started these databases to highlight potential studies to be included in the systematic review: PubMed, Google Scholar, Scopus.

The following research terms were included: "Osteosarcoma of the jaw", "Osteosarcoma head neck", "Osteosarcoma of the jaw X-ray appearance", "Tumors head neck diagnosis". Articles whose dealings were not related to the human being and non-English articles were excluded.

We considered studies that enrolled children and adults, with a fairly wide age range, of both sexes, in which the diagnosis of osteosarcoma of the jaw was explicitly expressed, in which was expressed the X-ray description and the framing of the patient at the anamnestic and therapeutic level.

\section{SELECTION OF STUDIES}

The title and abstract of the articles obtained from database searches were independently selected and evaluated by the authors of the review to determine whether they met with the inclusion criteria. For articles that seemed to meet with the inclusion criteria or for which there was insufficient information in the title or abstract, to make a decision clear, the whole treatment was read right away. In general, the auditors agreed on the selection. All the studies selected in accordance with the inclusion criteria were then evaluated and subjected to data extraction. We also noted that all the articles that have come to this stage of elaboration have been mentioned several times in the scientific literature and deal with studies carried out in different parts of the world (India, Korea, USA, Europe) with the aim of showing the incidence and epidemiology of the pathology as completely as possible in relation to ethnic differences and social habits.

The inspection of the various databases produced initially 952 results. These were screened using the selection criteria and filters described above. Articles that met with the criteria were reviewed to determine whether there was relevant patient information, if not present the article was excluded from the review (30 items remaining as a result of this step). The collected data was added to a document shared between the reviewers and then submitted to colleagues (Fig-1). 


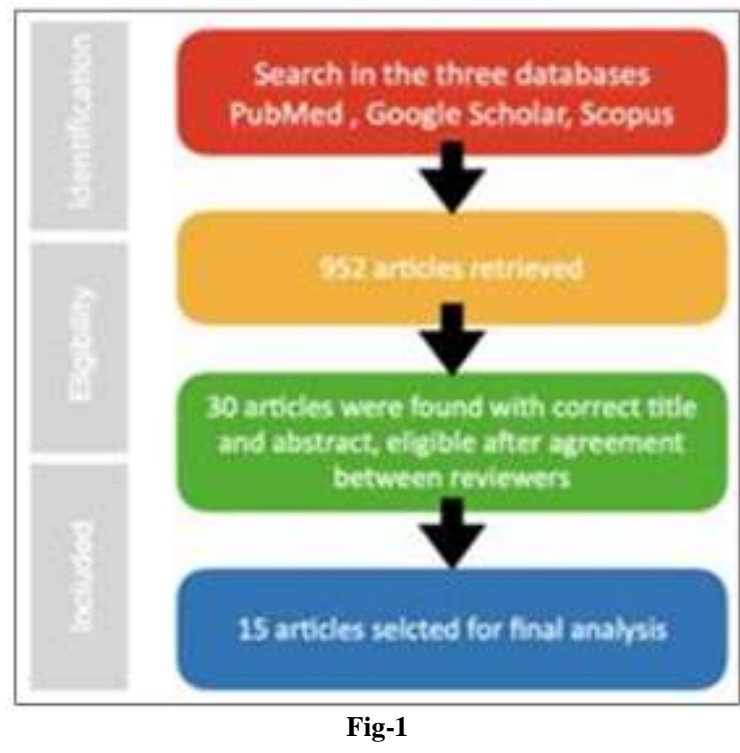

As a result of the application of search filters and the detailed examination of titles and abstracts, the number of interesting articles has been reduced to about 30, designated to full-read of the text. They were all considered for literature review on the subject, but only 15 studies presented an appropriate anamnestic, diagnostic and therapeutic framework, allowing us to extract scientific data to be screened and re-proposed in our review. In particular 7 case reports and 8 case series and cohorts.

\section{RESULTS \\ Patient Framing}

Analyzing the various articles, it emerged that the average age of incidence of the disease is between 14 and 50 years $[1-3,6,8]$ with rare exceptions where manifestations can be held even in the youngest/child age [5].

This type of disorder was found to have almost overlapping repercussions in males and females $(49.9 \%$ M: $50.1 \%$ F) [13] although with a slight increase in the latter. This can also be seen in the study conducted by Rui Fernandes in the Journal of Oral and Maxillofacial surgery, in which there is a 6:10 (Males:Females) proportion.

While a match between the various articles could be found from an age and gender point of view, the analysis of risk factors and triggers enlightened that there were different aspects. In some cases, it was noticed a correlation with genetic syndromes such as Li-Fraumeni syndrome [2] and Sjogren's syndrome [1]. While assessing the clinical history of patients, it also emerged that the onset of some osteosarcomas at the jaw level is associated with cancer treatments with radiotherapies (incidence of $0.084 \%$ art [11] or chemotherapy for previous injuries $[2,3,11]$.
In rare cases, it has emerged an association with facial traumas due to collision with cars, bicycles or even while performing sports and recreational activities [6]. An example is the study conducted by Garrirgton et al., [6] on 56 people, 9 of whom were around 28 years and had jaw tumours. Moreover, they reported episodes of trauma in the head-neck district at the time of the collection of anamnestic data.

What has emerged in the analysis of the various articles is that the assessment and identification of the lesion, such as a single primary tumor or metastatic form of other lesions, is not easy and clear to perform [1].

\section{Symptoms and Signs}

Diagnosis of osteosarcoma of the jaw is difficult both because of its rare onset and for the symptoms and signs that very often can lead to entering differential diagnosis with disorders more attributable to the level of dental elements.

The most common symptom of presentation is site-specific swelling [2, 6, 12, 9, 14] but it can then expand and also involve areas close to the lesion [9].

If this manifestation is represented in a meaningful way it can also lead to a situation of facial asymmetry $[9,12]$.

An example of severe facial asymmetry, followed by marked swelling at the level of the left cheek, is the case report of a 23-year-old boy of Moroccan origin described by Akerzoul et al., in the article "Osteosarcoma of the Jaw" [12].

Other symptoms are attributable to OSJ. One of the most relevant in addition to swelling is the pain sensation that turns out to be localizable at the level of the lesion and with repercussions on the dental elements $[2,6,9,14]$. If the tumor mass is in close correspondence with the teeth, it may also cause a separation of them and problems on the periodont ligament causing an enlargement and loss of support capacity $[2,6]$.

In addition to the most common symptoms, manifestations such as hypoesthesia [12, 15], nasal obstructions, headaches, visual problems, paresthesia and bleeding of palpation injury have been traced (Table-1) $[2,6,9,10]$. 
Table-1: Frequency Presenting Symptoms Osteosarcoma of the Laws

\begin{tabular}{|c|c|}
\hline $\begin{array}{c}\text { Symptom } \\
\text { mass, etc. }\end{array}$ & 16 \\
\hline Pain & 5 \\
\hline Loose teeth & 3 \\
\hline Toothache & 2 \\
\hline Bleeding & 1 \\
\hline Nasal obstruction & 3 \\
\hline Separated theeth & 1 \\
\hline Headache & 1 \\
\hline Eye "watering" & 1 \\
\hline No reported & 2 \\
\hline
\end{tabular}

It is rare the situation where there is an OSJ and you have no symptoms or visible sign [8].

\section{RADIOGRAPHICAL AND HISTOLOGICAL ASPECTS}

In order to be able to arrive at a correct diagnosis of OSJ of the jaw, in most studies the approach includes:

A. Objective examination of signs and symptoms

B. Analysis of detectable information by imaging (x-rays)

C. Histological examinations

D. Immunohistochemical examinations

X-ray images can show the presence of a widening of the periodontal ligament and a "sunbeam" scheme is very often associated with it $[2,6,8,9]$

Taking into account the analyses made in the study conducted by Rui Fernandes et al., [2] in the Journal of Oral and Maxillofacial Surgery, $45 \%$ of subjects noted the impacts of the support of dental elements (5 out of $11 \mathrm{X}$-rays) and an incidence of 55\% of the sunbeam appearance (6 out of 11 patients).

Thanks to imaging tests it is also possible to evaluate the degree of expansion, shape and margins of the tumor lesion.

These aspects are useful for the diagnostic situation but above all prognostic one, because the increase of tumor size leads to a reduction in overall survival $(\mathrm{P}=0.0167)$. In the study of Megan Granowski-LeCornu et al., [3] the tumors were classified as I (8/47), II (28/47) and III (11/47). Higher grade tumors had reduced overall survival $(P=0.01)$ [3].

As regards the extension, lesions have been identified that in more advanced stages had already involved the maxillary sinus, part of the lower orbital rim up to a portion of the temporal bone $[9,14]$.

No analogies were found about the extent of the lesion but dimensions ranging from a few $\mathrm{mm}$ up to $5 \mathrm{~cm}[1,3,9,14,12]$.

The margins of the lesions according to the severity are more defined and easily visible if the pathology is already in an advanced stage, while more radiolucent if the lesion is in the initial stages.

It has been possible to notice a division at radiographic level into three typologies: sclerotic, lithic or mixed. In some cases the calcification and lysis areas are mixed. An early osteosarcoma of the jaws can show a periodontal membrane space, symmetrically enlarged, who is around one or more teeth and it can be noticed by a periapical dental radiograph, before showing any other prominent radiographic evidence of its presence [6].

In some cases, however, it may happen that with a type of instrumental imaging the lesion appears unclear and this could lead to a risk of underestimation.

An example is the case of an 11-year-old boy examined in the study of Aya Yamamoto et al., [5], where the first diagnosis made was clinically nonspecific stomatitis.

In this case, unclear alterations were found in the Rx images, and there were no anomalies in the jaw bone or in the dental elements.

Even occlusal radiographs did not reveal evidence of a mass lesion on the palate or abnormal results in the roots of the incisors. It was necessary to use CT and RM to highlight maxillary lesions, and making diagnosis possible. The internal structures were slightly uneven and its density was less than the muscle. The sectional images revealed that the lesion was not in contact with the nasopalatin canal.

The lesion was represented by a low intensity signal on $\mathrm{T} 1$ weighted images (T1W) and high signal intensity on $\mathrm{T} 2$ weighted (T2W), that is images with suppression of the lipid component.

Also in the study of Prabhusankar et al., [9] the patient underwent an Orthopantomography and a cone beam computed tomography (CBCT). In this case, it was recognized the typical "solar ray" aspect, also discovering that the tumor involved the entire maxillary sinus and extended superiorly on the lower orbital rim. The posterior extension was seen up to the pterygoid 
plaques and the medial extension up to the lateral wall of the nose.

The description reported by Akerzoul et al., Was very detailed [15], regarding a 24-year- old man with jaw osteosarcoma.

Radiographic evaluation included:

- Panoramic radiography showing an osteocondensing image, extending from the incisor region to the molar region.

- A CT scan (CT), which confirmed the existence of a tumor process with heterodense aspect, containing a hyperdense component with an isodense component in the periphery, developed at the expense of the left maxillary bone. Tumor process reached the upper limit of the maxillary bone.

- A biopsy was performed under local anesthesia, and histological examination showed that it was a sarcomatous process, of chondroid nature, suggesting the diagnosis of chondrosarcoma.

Other less frequent aspects related to tumor lesion have been identified such as:

- Vascular invasion (5 cases), focal necrosis (21 cases) and hemorrhage (9 cases) [3].

- Possible lymph node involvement and lung deposits $(4.7 \%)$ [16].

Through biopsy it was also possible to perform a histological evaluation thanks to which it was possible to classify the various subtypes and the degree of differentiation of OSJ found. Different typologies have been detected throughout the studies.
In some of them, the main histotype is the chondroblastic (8 out of 11 cases) [2], in other articles instead it is the osteoblastic [3] or osteosarcoma NOS type $(68.8 \%)$ [13].

With new generation investigations of immunohistochemistry, it was then possible to discover that some tumor forms were highly positive for vimentin, alpha-actin, nuclear protein Ki-67 [5, 8].

These relevances are significant in establishing the type of therapeutic treatment and disease prognosis.

\section{Therapy}

Therapeutic approaches were different in the studies examined, although surgery was found to be the primary treatment modality. The term "local surgery" is used for procedures such as excisional biopsy, simple curettage or excision of a small block of tissue.

The term "radical surgery" in the jaw indicates that the treatment consists of a radical surgical removal with a large margin around the apparent tumor.

To make more clear the reading and understanding of the data, we have decided to include a table containing both the data of the therapies, the interventions carried out and the implications of these protocols on patient mortality (Table-2).

$$
\begin{aligned}
& \text { p. }=\text { patients } \\
& \text { C. = UNSPECIFIED surgery } \\
& \text { C.L. = Local Surgery } \\
& \text { C.R. = Radical Surgery } \\
& \text { A. = Adjuvant } \\
& \text { N. = Neoadjuvant } \\
& \text { T. = Treatment }
\end{aligned}
$$

\begin{tabular}{|c|c|c|c|c|c|c|c|c|c|}
\hline & & Study (6) & $\begin{array}{l}\text { Study } \\
(2)\end{array}$ & Study (3) & $\begin{array}{l}\text { Study } \\
\text { (11) }\end{array}$ & $\begin{array}{l}\text { Study } \\
(16)\end{array}$ & $\begin{array}{l}\text { Study } \\
\text { (13) }\end{array}$ & $\begin{array}{l}\text { Study } \\
(17)\end{array}$ & $\begin{array}{l}\text { Study } \\
\text { (7) }\end{array}$ \\
\hline & Total Sample & $\begin{array}{l}56 \text { of which } \\
\text { we have the } \\
\text { data of } 47\end{array}$ & $14 \mathrm{p}$. & $\begin{array}{l}\text { Group } 1=30 p \\
\text { Group } 2=17 p \\
\text { Total } 47 p\end{array}$ & $45 \mathrm{p}$. & 21 & 541 & 18 & $26 \mathrm{p}$ \\
\hline & Total period of observation & & & & 1.4 years & 7 years & 38 years & 20 years & 6 years \\
\hline & Male & $31 \mathrm{p}$. & $6 \mathrm{p}$ & & $33 \mathrm{p}$. & $10 \mathrm{p}$. & $49,95 \%$ & $11 \mathrm{p}$. & $9 \mathrm{p}$. \\
\hline & Female & $24 \mathrm{p}$. & $10 \mathrm{p}$. & & $12 \mathrm{p}$. & $11 \mathrm{p}$. & $50.1 \%$ & $7 \mathrm{p}$ & $17 \mathrm{p}$. \\
\hline & Average age of patients at diagnosis & $27 \mathrm{YO}$ & & $30,9 \mathrm{YO}$ & $49 \mathrm{YO}$ & $29.7 \mathrm{YO}$ & $41,3 \mathrm{YO}$ & $42 \mathrm{YO}$ & $32 \mathrm{YO}$ \\
\hline & Average tumor size & & & $4,38 \mathrm{~cm}$ & $5 \mathrm{~cm}$ & $2-13 \mathrm{~cm}$ & & & \\
\hline & Jaw localization & $16 \mathrm{p}$. & $7 \mathrm{p}$. & $24 \mathrm{p}$. & $33 \mathrm{p}$. & $6 \mathrm{p}$. & $55,6 \%$ & $6 \mathrm{p}$. & $5 \mathrm{p}$ \\
\hline & Mandible localization & $38 \mathrm{p}$. & $9 \mathrm{p}$. & $23 \mathrm{p}$. & $12 \mathrm{p}$. & $15 \mathrm{p}$ & $44,4 \%$ & $12 \mathrm{p}$. & $21 \mathrm{p}$ \\
\hline 1 & No treatment & & & & & & $10.7 \%$ & & \\
\hline 2 & Unknown treatment & & & & & & $3,9 \%$ & & \\
\hline 3 & Radiotherapy & $1 \mathrm{p}$. & & & & & $3.7 \%$ & & \\
\hline 4 & Chemotherapy & & & & $6 \mathrm{p}$. & & & $2 \mathrm{p}$. & \\
\hline 5 & Chemotherapy + Radiotherapy & & & & & & & & $3 \mathrm{p}$. \\
\hline 6 & $\begin{array}{llll}\begin{array}{l}\text { Chemotherapy } \\
\text { (Unspecified) }\end{array} & \text { N. } & + & \text { Surgery } \\
\end{array}$ & & & Group $2=14$ & & $2 \mathrm{p}$ & & $6 \mathrm{p}$ & $4 \mathrm{p}$. \\
\hline 7 & Surgery (Unspecified) & & $10 \mathrm{p}$. & & $30 \mathrm{p}$. & & $59.1 \%$ & $4 \mathrm{p}$. & \\
\hline 8 & C. + Radiotherapy A. & & & $23 \mathrm{p}$. & & & $22.6 \%$ & & \\
\hline 9 & C. + Chemotherapy A. & & $4 \mathrm{p}$. & $28 \mathrm{p}$. & $8 \mathrm{p}$. & $5 p$. & & & $16 \mathrm{p}$. \\
\hline 10 & $\begin{array}{l}\text { C. + Chemotherapy A. + radiotherapy } \\
\text { A. }\end{array}$ & & & & $1 \mathrm{p}$. & & & $6 \mathrm{p}$ & $3 \mathrm{p}$. \\
\hline 11 & $\begin{array}{l}\text { Chemotherapy N. + C. + } \\
\text { Chemiotherapy A. }\end{array}$ & & & & & $5 \mathrm{p}$. & & & \\
\hline
\end{tabular}

Table-2 


\begin{tabular}{|c|c|c|c|c|c|c|c|c|c|}
\hline 12 & Local Surgery & & & & & $11 \mathrm{p}$. & & & \\
\hline 13 & C. L. + Radiotherapy A. & $5 \mathrm{p}$. & & & & & & & \\
\hline 14 & C. L. + Chemiotherapy A. & & & & & & & & \\
\hline 15 & Radical Surgery & $23 \mathrm{p}$. & & & & $10 \mathrm{p}$. & & & \\
\hline 16 & C. R. + Radiotherapy A. & $7 \mathrm{p}$. & & & & & & & \\
\hline 17 & C. R. + Chemiotherapy A. & $1 \mathrm{p}$. & & & & & & & \\
\hline 18 & C.R. + Neck dissection & $6 \mathrm{p}$. & & & & & & & \\
\hline 19 & $\begin{array}{l}\text { C. R. + Radiations A. + } \\
\text { Chemiotherapy A. }\end{array}$ & $3 \mathrm{p}$. & & & & & & & \\
\hline 20 & $\begin{array}{l}\text { C. R. + Neck dissection + } \\
\text { Radiations A. }\end{array}$ & $1 \mathrm{p}$. & & & & & & & \\
\hline 21 & $\begin{array}{l}\text { C. R. }+ \text { Neck dissection }+ \\
\text { Radiations A. }+ \\
\text { chemiotherapy } \\
\text { A. } \\
\end{array}$ & $1 \mathrm{p}$. & & & & & & & \\
\hline & Post treatment follow up & 7-11 years & $\begin{array}{l}14 \\
\text { months - } \\
108 \\
\text { months }\end{array}$ & $\begin{array}{l}5 \\
\text { years }\end{array}$ & & 19,3 months & & $\begin{array}{l}26 \\
\text { months }\end{array}$ & $\begin{array}{l}24 \\
\text { months }\end{array}$ \\
\hline & Mortality & $\begin{array}{l}\text { Post T. } 3: 1 \mathrm{p} . \\
\text { Post T. 10: } 4 \mathrm{p} . \\
\text { Post T. 15: } 17 \mathrm{p} . \\
\text { Post.T. } 16: 5 \mathrm{p} . \\
\text { Post T. } 17: 1 \mathrm{p} . \\
\text { Post T. 18: } 4 \mathrm{p} . \\
\text { Post.T. } 19: 3 \mathrm{p} \\
\text { Post T. } 20: 0 \mathrm{p} . \\
\text { Port T. } 21: 0 \mathrm{p} .\end{array}$ & $2 \mathrm{p}$. & $32 \%$ & $\begin{array}{l}\text { A } 1 \text { year } \rightarrow \\
46.7 \% \\
\text { A } 2 \text { years } \rightarrow \\
64.4 \% \\
\text { A } 3 \text { years } \rightarrow \\
86.5 \%\end{array}$ & $\begin{array}{l}3 \text { deaths out of } \\
17 \text { cases } \\
\text { (excluding } 4 \\
\text { patients who did } \\
\text { not follow up } \\
\text { after surgery) }\end{array}$ & $\begin{array}{l}\text { Post T. 1: } \\
\text { 98.9\% } \\
\text { Post T. 3: } \\
\text { 98.9\% } \\
\text { Post T. 7: } \\
86.7 \% \\
\text { Post T. 8: } \\
93,8 \%\end{array}$ & $22 \%$ & $16 \%$ \\
\hline
\end{tabular}

In study [2] cispalatin and adriamycin were used as chemotherapy.

In study [6] Cytoxan, 5-fluoruracil, Methotrexate were used as chemotherapy; in treatment 19 and 21, Sarcolysine.

In study [16] the chemotherapy regimens were in the form of 4-7 cycles of cisplatin or carboplatin plus doxorubicin, except for one case that received 6 cycles of methotrexate- based regimen.

\section{DISCUSSION}

As indicated by the studies examined, osteosarcoma of the jaws is an infrequent pathology and survival rates are more unfavorable than patients suffering from the same disorder but at the mandible level. This observation is supported by the study of Garrignton et al., [6] showing that for the 47 patients with complete follow-up information, the average survival time for those with mandibular osteosarcoma was 6.5 years, compared with 2.9 years for those with maxillary osteosarcoma.

Beyond this general statement on the prognosis of mandibular and maxillary osteosarcoma, however, a notable difference in survival rates has been observed for specific sites of origin within each of the 2 types. Patients with tumors located in the maxillary antrum seem to have an extremely poor prognosis, as reported by the study by Garrignton et al., [6] in which none of the 4 patients with antral osteosarcoma lived for more than a year after the definitive therapeutic treatment. In contrast, 3 out of 8 patients with osteosarcoma insurgent in the maxillary alveolar ridge survived for 5 years or more. It seems reasonable to think that the different survival rate is linked to the time of discovery of the neoplasm and to the possibility of undergoing surgery, aspects in turn influenced by the specific site where the tumor mass develops. An example is the ease in self-examination in the case of nodules in the mandibular area unlike in the maxillary area. Except for the few individuals whose osteosarcoma is discovered during a routine examination, patients are notoriously seeking for control and advice only when they notice clear abnormalities, such as nodules, dental mobility, unusual pain or numbness [6].

As can be seen from the data extrapolated from the various studies examined, the two most frequent clinical signs are pain and swelling [12].

The swelling has an elastic consistency, it's solid, painless, covered by a normal or slightly congested large mucosa, which can deform the face. As regards pain, the initial symptoms are frustrating but no clinical sign allows the doctor to suspect sarcomatous origin. In addition to this we can also find dental manifestations (mobility, pain, spontaneous loss of some elements), sensory disturbances (hypoaesthesia or anesthesia) in the territory of the infraorbital nerve. There may also be a nasal obstruction, epistaxis, sometimes exophthalmos $[1-3,9,12]$

\section{RADIOGRAPHIC EVIDENCE}

Our review aims at giving a complete picture of osteosarcoma of the jaws, particularly reporting the specific radiographic aspects of the pathology and of common feedback for the clinician. 
Radiographically, osteosarcoma exhibits various aspects. In fact, it can present itself as a lytic, sclerotic or mixed lytic-sclerotic lesion with undefined edges. Some osteosarcomas show a periosteal reaction that manifests itself as a sun-ray pattern caused by irradiation of mineralized tumor spicules or by a triangular increase in the periosteum (Codman's triangle) $[1,2,8]$.

Furthermore, the expansion of the periodontal ligament secondary to the invasion of the tumor and reabsorption of the tooth root in correspondence with the neoplastic lesion can be observed in many cases [8, 12].

Another feature of the neoplasm is the destruction of the cortex with invasion of the adjacent soft frank tissue [8]. Computed tomography with multiple detectors is useful in this sense, to identify the extent of bone destruction and the involvement of the soft tissues of the lesion.

Unfortunately, despite some peculiar characteristics, conventional radiographies provide limited information in the evaluation of osteosarcomas due to overlapping bone structures [8].

TC and MRI techniques can help in this situation. The lesions may be characterized by a low intensity signal on T1 weighted images (T1W) and high signal intensity on $\mathrm{T} 2$ weighted (T2W) images, or images with suppression of the lipid component. The edges of the lesion may appear unclear and undefined, and the internal structures uneven. The tomographic images (weighed by the detection of soft tissues or bone tissue) evaluate the size of the tumor, its limits, the presence or absence of intratumoral calcifications, the density of the tumor (before and after the intravenous injection of the medium of contrast), erosion and destruction of bones. The weighted tomographic images for the detection of soft tissues are particularly useful for the evaluation of the spicular periosteal response and for the invasion of the soft tissues of a neoplasm [5, 8].

Osteosarcoma is classified into osteoblastic, chondroblastic and fibroblastic. Among these histological subtypes, osteoblastic osteosarcoma represents most of the maxillary osteosarcomas, while fibroblastic osteosarcoma rarely affects the jaws [1-3, $11,9,13]$.

\section{DIFFERENTIAL DIAGNOSIS}

The features that can be highlighted radiographically for osteosarcoma are often unclear and can also be found for other types of lesions that therefore enter into differential diagnosis. Some examples are: chondrosarcoma [8, 18-23], osteomyelitis $[8,18,19,24]$, Ewing's sarcoma [18, 19, 21], periapical abscess [24, 25], ameloblastoma [2], fibrous dysplasia
$[8,18,19,26]$ and even lesions that are usually not represented in the maxillary bones, such as fibrosarcoma [8, 18, 19, 26, 27], leiomyosarcoma [18, 19], rhabdomyosarcoma $[15,26]$.

Osteomyelitis can have an odontogenic or hematological origin. Radiologically it is highlighted as a lytic lesion with associated periosteal reaction. However, the periosteal reaction is typically laminar, contrary to what happens in osteosarcomas with spicules perpendicular to the cortex.

When internal radiopacities are present in the tumor, chondrosarcoma should be considered as a differential diagnosis. Occasionally, fibroblastic osteosarcoma can have pleomorphic nuclei and looks like the malignant fibrous histiocytoma. However, the presence of even a small amount of osteoid matrix distinguishes fibroblastic osteosarcoma from the neoplasms indicated above $[1,8]$.

The Ewing sarcoma tumor family (ESFT) includes a group of highly aggressive, morphologically similar malignant neoplasms that share a common spontaneous genetic translocation that primarily affects children and young adults. These predominantly small round cell tumors include Ewing's sarcoma of bone and soft tissue, as well as primary neuroectodermal tumors (PNET) involving bone, soft tissues and the thoracopulmonary region [28].

Also regarding the histological aspect, some differential diagnoses emerged including fibro-bone lesions such as fibrous dysplasia [8, 27], fibrosarcoma $[8,18,19,26,27]$ and malignant fibrous histiocytoma [8].

Clinically, osteosarcomas may present characteristics similar to some inflammatory periapical lesions, such as periapical abscess. In fact they also present pain, swelling and radiographic changes. However, the positive response to pulp viability tests in osteosarcoma suggests the absence of root canal infection $[24,25]$.

\section{THERAPEUTIC CONCLUSIONS}

Early diagnosis and adequate surgical resection are essential for survival, with local diffusion control ensuring short-term survival. Where adequate resection is possible, only local or radical surgery is adequate, while adjuvant therapy should be considered when the surgical margins are not free of neoplastic cells. It is therefore possible in addition to use neoadjuvant and / or adjuvant chemotherapy $[1-3,16$, $13,17,29]$.

In the studies examined only in few cases chemotherapy and radiotherapy were used independently $[11,13,17]$. On the contrary, surgical intervention with subsequent or preventive intake of 
chemotherapy $[2,3,11,16,7]$ or radiotherapy $[3,13]$ or both is much more common and effective $[11,17,7]$.

Early detection and aggressive treatment are the keys to higher survival rates. In operable tumors, treatment includes partial / subtotal / total maxillectomy / mandibulectomy and reconstruction of the area using free flaps of the bone skin composite from the fibula / scapula / hip as the donor site $[1,13]$.

Due to easier resectability and the ability to obtain negative surgical margins, mandibular osteosarcomas have a better prognosis than jaw tumors. Granowski-LeCornu [3, 29] confirmed a worse outcome for maxillary tumors, related to the difficulty of obtaining adequate resection margins, leading to a higher incidence of local recurrence, residual disease and death. Long-term survival depends on variables such as local recurrence, intracranial invasion and the presence of metastases.

While adjuvant chemotherapy may improve early survival, neither chemotherapy nor radiation therapy appears to affect long-term survival, although the literature is divided on this point [13]. Since positive surgical margins are associated with an unfavorable prognosis, some authors have shown that the use of multimodal therapy can significantly reduce local recurrence rates and thus improve survival [29].

\section{CONCLUSIONS}

Osteosarcoma of the jaw is a difficult lesion to treat both in the diagnosis phase and in management due to the high incidence of incorrect biopsy results; specific radiological features are rare and there is difficulty in correct resection due to proximity to vital structures.

The probability of healing in osteosarcomas of the jaws has been estimated from $60 \%$ to $70 \%$ [28]. However palliative resection, when possible, offers the potential for immediate improvement in the quality of life, including the ability to reintegrate with society, feed and regain the word, and a high degree of selfesteem and acceptance.

The main concerns related to surgical management, particularly in children and adolescents, include deleterious effects on respiratory function, nutrition and swallowing, language and vision, as well as general appearance of the face and cosmetics. On the other hand, the use of modern surgical techniques, the implementation of microvascularized flaps, immediate reconstruction with PEEK (polyetheretherketone) implants, titanium grid plates, Medpore sheets reinforced with titanium, obturation prosthesis, dental prostheses and other reconstructive surgical materials, often allow the surgeon to obtain excellent functional and aesthetic results.
The topic just discussed is an aspect of extreme importance in the dental field, as it will influence the approach and future therapies. The dentist is a crucial figure in the early diagnosis of osteosarcoma. Thanks to the correct and scrupulous observation of the patient's panoramic radiographs, lesions characteristic of this pathology can be identified, qualifying the patient for a timely intervention and with greater possibilities of resolution.

\section{REFERENCES}

1. Bousdras VA, Flanagan A, Bousdras KA, Vourvachis M, Newman L, Kalavrezos N. Multiple-site osteosarcomas of the jaw in a single patient. A true case of a metachronous lesion? International journal of oral and maxillofacial surgery. 2010 Jul 1;39(7):733-6.

2. Fernandes R, Nikitakis NG, Pazoki A, Ord RA. Osteogenic sarcoma of the jaw: a 10-year experience. Journal of Oral and Maxillofacial Surgery. 2007 Jul 1;65(7):1286-91.

3. LeCornu MG, Chuang SK, Kaban LB, August M. Osteosarcoma of the jaws: factors influencing prognosis. Journal of oral and maxillofacial surgery. 2011 Sep 1;69(9):2368-75.

4. Chaudhary M, Chaudhary SD. Osteosarcoma of jaws. J Oral Maxillofac Pathol, 2012; 16:233-8.

5. Yamamoto A, Sakamoto J, Muramatsu T, Hashimoto S, Shibahara T, Shimono M, Sano T. Osteosarcoma of maxilla with unusual image findings in child. The Bulletin of Tokyo Dental College. 2011;52(4):201-7.

6. Garrington GE, Scofield HH, Cornyn J, Hooker SP. Osteosarcoma of the jaws. Analysis of 56 cases. Cancer, 1967; 20(3):377-91.

7. Jeong HI, Lee MJ, Nam W, Cha IH, Kim HJ. Osteosarcoma of the jaws in Koreans: analysis of 26 cases. Journal of the Korean Association of Oral and Maxillofacial Surgeons. 2017 Oct 1;43(5):312-7.

8. Tahmasbi-Arashlow, M., Barnts, K. L., Nair, M. K., Cheng, Y. S. L., \& Reddy, L. V. (2019). Radiographic manifestations of fibroblastic osteosarcoma: A diagnostic challenge. Imaging science in dentistry, 49(3), 235-240.

9. Prabhusankar K, Karande A, Jerry JJ, Rishal Y. Osteosarcoma of the posterior maxilla. Journal of International Society of Preventive \& Community Dentistry. 2016 Aug;6(Suppl 2):S171-4.

10. Akbiyik N, Alexander LL. Osteosarcoma of the maxilla treated with radiation therapy and surgery. Journal of the National Medical Association. 1981 Apr;73(4):355-6.

11. Liao LQ, Yan HH Mai JH, Liu WW, Li H1,Guo ZM1, Zeng ZY, Liu XK. Radiation-induced osteosarcoma of the maxilla and mandible after radiotherapy for nasopharyngeal carcinoma. Chin J Cancer. 12 Oct 2016; 35(1):89.

12. Akerzoul N, Chbicheb S, Oujilal A. Osteosarcoma of the Jaw: AC ase Report. Int J Dent Med Res| 
MAR-APR. 2015;1(6):60.

13. Lee RJ, Arshi A, Schwartz HC, Christensen RE. Characteristics and prognostic factors of osteosarcoma of the jaws: a retrospective cohort study. JAMA Otolaryngol Head Neck Surg, 1 May 2015; 141(5):470-7.

14. Chabchoub I, Gharbi O, Remadi S, Limem S, Trabelsi A, Hochlef M, Ben Fatma L, Landolsi A, Mokni M, Kraiem C, Ben Ahmed S. Postirradiation Osteosarcoma of the Maxilla: A Case Report and Current Review of Literature. J Oncol, 2009.

15. Akerzoul N, Chbicheb S, Oujilal A. Osteosarcoma of the Jaw: AC ase Report. Int J Dent Med Res| MAR-APR. 2015;1(6):60-64.

16. ElKordy MA, ElBaradie TS, ElSebai HI, Amin AA, KhairAlla SM. Osteosarcoma of the jaw: challenges in the diagnosis and treatment. Journal of the Egyptian National Cancer Institute. 2018 Mar 1;30(1):7-11.

17. Eder-Czembirek C, Moser D, Holawe S, Brodowicz T, Ries J, Sulzbacher I, Selzer E. Osteosarcoma of the jaw-experience at the Medical University Vienna and comparative study with international tumor registries. Clinics. 2019;74, e701.

18. Amaral MB, Buchholz Í, Freire-Maia B, Reher P, de Souza PE, Marigo Hde A, Martins CR, Horta MC. Advanced osteosarcoma of the maxilla: a case report. Med Oral Patol Oral Cir Bucal. 2008 Aug 1;13(8):E492-5.

19. Praveena NM, Maragathavalli G. Osteosarcoma of Maxilla. J India Aca Oral Med Radio, Mar 2018; 30(1):7-11 .

20. Thorn D, Mamot C, Krasniqi F, Metternich F, Prestin S. Multimodality treatment in ewing's sarcoma family tumors of the maxilla and maxillary sinus: review of the literature. Sarcoma. 2016 Jun 16;2016.

21. Yogesh TL, Shetty A, Keswani H, Rishi D.
Aggressive high-grade Ewing's sarcoma of maxilla: A rare case report. Journal of Oral and Maxillofacial Pathology: JOMFP. 2018 Jan;22(Suppl 1):S48-S53.

22. Mokhtari S, Mirafsharieh A. Clear cell chondrosarcoma of the head and neck. Head \& Neck Oncology. 2012 Dec;4(1):1-5.

23. Unal A, Yurtsever Kum N, Kum RO, Erdogan A, Ciliz DS, Guresci S, Ozcan M. Giant Cementoossifying Fibroma of the Maxilla. Tumori, 14 Nov 2015, 101(6): e163-6.

24. Prasad K, Dexith J, Lalitha RM, Ranganath K, Shuba R, Kumari MK, Mysorekar V. Maxillary osteosarcoma masquerading as chondromyxoid fibroma: report of a case. Journal of maxillofacial and oral surgery. 2015 Mar 1;14(1):87-92.

25. Yamamoto-Silva FP, Silva BS, Batista AC, Mendonça EF, Pinto-Junior DD, Estrela C. Chondroblastic osteosarcoma mimicking periapical abscess. Journal of Applied Oral Science. 2017 Aug;25(4):455-61.

26. Sinha R, Chowdhury SR, Chattopadhyay PK, Rajkumar K. Low-grade osteosarcoma of the mandible. Journal of maxillofacial and oral surgery. 2010 Jun 1;9(2):186-90.

27. Song W, van den Berg E, Kwee TC, Jutte PC, Cleton-Jansen AM, Bovée JV, Suurmeijer AJ. Low-grade central fibroblastic osteosarcoma may be differentiated from its mimicker desmoplastic fibroma by genetic analysis. Clinical sarcoma research. 2018 Dec;8(1):1-8.

28. Mendenhall WM, Fernandes R, Werning JW, Vaysberg M, Malyapa RS, Mendenhall NP. Head and neck osteosarcoma. American journal of otolaryngology. 2011 Nov 1;32(6):597-600.

29. Nthumba PM. Osteosarcoma of the jaws: a review of literature and a case report on synchronous multicentric osteosarcomas. World journal of surgical oncology. 2012 Dec 1;10(1):240. 